\title{
Spondyloepimetaphyseal dysplasia with multiple dislocations
}

INSERM

\section{Source}

INSERM. (1999). Orphanet: an online rare disease and orphan drug data base. Spondyloepimetaphyseal dysplasia with multiple dislocations. ORPHA:93360

Spondyloepimetaphyseal dysplasia with multiple dislocations is a rare genetic primary bone dysplasia disorder characterized by midface hypoplasia, short stature, generalized joint laxity, multiple joint dislocations (most frequently of knees and hips), limb malalignment (genu valgum/varum) and progressive spinal deformity (e.g. kyphosis/scoliosis). Radiography reveals distinctive slender metacarpals and metatarsals, as well as small, irregular epiphyses, metaphyseal irregularities with vertical striations, constricted femoral necks and mild platyspondyly, among others. 